\title{
Study on Design Method of Joint Panels for Hybrid Railway Rigid-frame Bridges
}

\author{
Satoshi EGUCHI
}

Researcher

\author{
Hisao NISHIDA \\ Researcher,
}

\section{Manabu IKEDA}

Assistant Senior Researcher,

\author{
Kiyomitsu MURATA \\ Senior Researcher,
}

Steel\&Hybrid Structures, Structures Technology Div.

Elevated railway bridges in urban areas are often constructed under spatial restrictions in a limited span of time. Thus, improved work efficiency and rapid work progress are essential requirements. Moreover, railway structures are required to show high fatigue and seismic resistance. The hybrid railway elevated bridge is a type of structure that meets such requirements. The authors have already proposed a method to evaluate the performance of the column of concrete filled steel tube (CFT) and beam of steel/reinforced concrete beam, which compose a hybrid railway rigid frame elevated bridge. However, there have been almost no studies on the joint of concrete filled steel tube column.

This paper discusses a design method of a newly developed beam-to-column insert joint, with cruciform steel and reinforcing bars inserted into CFT, on the basis of experimental study on its load bearing capability.

Keywords : hybrid structure, railway elevated bridge, insert joint, design method

\section{Introduction}

An ever increasing number of elevated railway bridges are being built in urban areas as part of projects to increase the transport capacity or construct continuous overhead crossings. These type of projects must be carried out in very restricted spaces surrounded by existing structures and within a short period of time at night when there is no train service. This results in high demands for a technique enabling more efficient and rapid work. In addition, structures have been required to be more seismically resistant since the Hyogoken Nanbu Earthquake caused serious damages.

Under these circumstances, the concrete filled steel tube (CFT) has come to the fore. Its essential merit is higher seismic performance providing a great load bearing capability and an excellent ductility. Furthermore, it realizes a shorter work period because steel tubes can be used as a form for concrete placing. Therefore it is frequently used for constructing columns and piles.

As a technique to join different materials of elevated hybrid rigid frame bridges, the insert joint has been devised, which offers ease of construction, labor-saving effect, and offsetting construction errors ${ }_{1}$. By the inset joint practice, inserts of cruciform steel and reinforcing bars (rebars) are made to penetrate to a specified depth in the CFT column, which transmit loads between beams and columns.

In the study reported here, for cases where bending fracture of the joint takes place before the column fails due to bending, the fracture mode of the joint was investigated through alternate loading tests, to review the load bearing capability of the insert joint already proposed.

\section{Alternate loading test of insert joint}

\subsection{Overview of the experiment}

The test specimen is a nearly $1 / 2$-scale model of the beam-column joint of an ordinary railway rigid frame elevated bridge. The standard column tube is $406.4 \mathrm{~mm}$ in diameter, and $6.4 \mathrm{~mm}$ in thickness (STK490). The Design strength of the filling concrete $\left(f^{\prime}{ }_{\mathrm{ck}}\right)$ is $24 \mathrm{~N} / \mathrm{mm}^{2}$. The strength of the joint is determined according to the Design standard for railway structures and commentary for Steel-concrete hybrid structures ${ }^{2)}$ (hereinafter referred to as "Hybrid Structure Design Standard"). The strength of the insert is assumed to be not more than the bending strength of the CFT member, so as to induce bending failure of the insert before the CFT member fracture. Table 1 and Figure 1 show the shape and characteristics of the test specimens.

Alternate horizontal loads were applied in the quasistatic manner to the loading point of column head. Specimens JTSC- 7 and 8 were subjected to constant compressive axial forces equal to the fully plastic compressive strength multiplied by a factor of 0.1 and 0.25 , then to horizontal loads.

Every specimen underwent the same loading pattern. The experimentally yielded displacement $\delta_{\mathrm{y}}$ was taken as the horizontal displacement of the loading point on the column head when the insert cruciform steel or rebars yielded. The displacement was gradually increased, at the amplitude of integral times of $\delta_{\mathrm{y}}$ in each direction, and three cycles per step. 
Table 1 Specifications of the specimens

\begin{tabular}{|c|c|c|c|c|c|c|c|c|c|c|}
\hline \multirow{2}{*}{\multicolumn{2}{|c|}{$\begin{array}{l}\text { Specimen } \\
\text { No. }\end{array}$}} & \multicolumn{8}{|c|}{ Steel tube } & \multirow{2}{*}{\begin{tabular}{l}
\multicolumn{1}{c}{ Inserts } \\
Insertion \\
length $(\mathrm{mm})$
\end{tabular}} \\
\hline & & $\begin{array}{l}\text { Tube diam } \\
(\mathrm{mm})\end{array}$ & & $\begin{array}{l}\text { hickness } \\
(\mathrm{mm})\end{array}$ & \multicolumn{2}{|l|}{ Type } & $\mathrm{D} / \mathrm{t}$ & \multicolumn{2}{|c|}{ Steel grade } & \\
\hline \multicolumn{2}{|c|}{ JTSC-1 } & 406.4 & & 4.0 & Ordinary & & 102 & \multicolumn{2}{|c|}{ SM490 } & 530 \\
\hline \multicolumn{2}{|c|}{ JTSC-2 } & 406.4 & & 6.4 & Ordinary & & 64 & \multicolumn{2}{|c|}{ STK490 } & 520 \\
\hline \multicolumn{2}{|c|}{ JTSC-3 } & 406.4 & & 9.0 & Ordinary & & 45 & \multicolumn{2}{|c|}{ SM490 } & 510 \\
\hline \multicolumn{2}{|c|}{ JTSC-4 } & 400.0 & & 9.0 & $\mathrm{w} /$ protrusic & & 44 & \multicolumn{2}{|c|}{ SKK490NR } & 510 \\
\hline \multicolumn{2}{|c|}{ JTSC-5 } & 406.4 & & 6.4 & Ordinary & & 64 & \multicolumn{2}{|c|}{ STK490 } & 520 \\
\hline \multicolumn{2}{|c|}{ JTSC-6 } & 406.4 & & 6.4 & Ordinary & & 64 & \multicolumn{2}{|c|}{ STK490 } & 520 \\
\hline \multicolumn{2}{|c|}{ JTSC-7 } & 406.4 & & 6.4 & Ordinary & & 64 & \multicolumn{2}{|c|}{ STK490 } & 520 \\
\hline \multicolumn{2}{|c|}{ JTSC-8 } & 406.4 & & 6.4 & Ordinary & & 64 & \multicolumn{2}{|c|}{ STK490 } & 520 \\
\hline \multicolumn{2}{|c|}{ JTSC-9 } & 406.4 & & 6.4 & Ordinary & & 64 & \multicolumn{2}{|c|}{ STK490 } & 520 \\
\hline \multicolumn{2}{|c|}{ JTSC-10 } & 406.4 & & 6.4 & Ordinary & & 64 & \multicolumn{2}{|c|}{ STK490 } & 520 \\
\hline \multirow[b]{2}{*}{ No. } & \multicolumn{4}{|c|}{ Inserts } & \multicolumn{6}{|c|}{ Parameters } \\
\hline & \multicolumn{3}{|c|}{$\begin{array}{r}\text { Cruciform steel } \\
(\mathrm{mm})\end{array}$} & Rebar & $\begin{array}{l}\text { Steel } \\
\text { ratio }\end{array}$ & \multicolumn{3}{|c|}{$\begin{array}{l}\text { Cruciform steel } \\
\text { / rebar ratio }\end{array}$} & $\begin{array}{l}\text { Axial force } \\
\text { ratio }\end{array}$ & Parameters \\
\hline 1 & \multicolumn{3}{|c|}{$\begin{array}{l}\mathrm{H} 260 \times 130 \times 6 \times 12 \\
(\mathrm{SM} 490)\end{array}$} & $\begin{array}{c}\text { D13-16 } \\
(\mathrm{SD} 345)\end{array}$ & 0.051 & \multicolumn{3}{|c|}{2.24} & 0 & Steel ratio \\
\hline 2 & $\begin{array}{l}\mathrm{H} 26 \\
(\mathrm{SM} \\
\end{array}$ & $\begin{array}{l}\times 130 \times 6 \times \\
90)\end{array}$ & & $\begin{array}{l}\text { D16-16 } \\
\text { (SD345) } \\
\end{array}$ & 0.078 & & 2.18 & & 0 & Standard \\
\hline 3 & $\begin{array}{l}\mathrm{H} 26 \\
(\mathrm{~S} M\end{array}$ & $\begin{array}{l}\times 130 \times 12 \\
0)\end{array}$ & & $\begin{array}{c}\text { D19-16 } \\
\text { (SD345) }\end{array}$ & 0.105 & & 1.97 & & 0 & Steel ratio \\
\hline 4 & $\begin{array}{l}\mathrm{H} 26 \\
(\mathrm{~S} M\end{array}$ & $\times 130 \times 12$ & & $\begin{array}{l}\text { D19-16 } \\
\text { (SD345) }\end{array}$ & 0.108 & & 1.97 & & 0 & $\begin{array}{l}\text { Tube } \\
\text { w/protrusions }\end{array}$ \\
\hline 5 & $\begin{array}{l}\mathrm{H} 28 \\
\text { (SM }\end{array}$ & $\begin{array}{l}\times 150 \times 12> \\
90)\end{array}$ & & $\begin{array}{l}\text { D10-16 } \\
\text { (SD345) }\end{array}$ & 0.082 & & 8.26 & & 0 & $\begin{array}{l}\text { Cruciform } \\
\text { steel/rebar ratio }\end{array}$ \\
\hline 6 & & & & $\begin{array}{l}\text { D22-24 } \\
\text { (SD345) }\end{array}$ & 0.072 & & 0.00 & & 0 & $\begin{array}{l}\text { Cruciform } \\
\text { steel/rebar ratio }\end{array}$ \\
\hline 7 & $\begin{array}{l}\mathrm{H} 26 \\
(\mathrm{SM}\end{array}$ & $\begin{array}{l}\times 130 \times 9 \times \\
90)\end{array}$ & & $\begin{array}{l}\text { D16-16 } \\
\text { (SD345) }\end{array}$ & 0.078 & & 2.18 & & 0.10 & Axial force ratio \\
\hline 8 & $\begin{array}{l}\mathrm{H} 26 \\
(\mathrm{~S} M\end{array}$ & $\begin{array}{l}\times 130 \times 9 \times \\
90)\end{array}$ & & $\begin{array}{l}\text { D16-16 } \\
\text { (SD345) }\end{array}$ & 0.078 & & 2.18 & & 0.25 & Axial force ratio \\
\hline 9 & $\begin{array}{l}\mathrm{H} 26 \\
(\mathrm{~S} M\end{array}$ & $\begin{array}{l}\times 130 \times 6 \times \\
70)\end{array}$ & & $\begin{array}{l}\text { D16-16 } \\
(\mathrm{SD} 345)\end{array}$ & 0.059 & & 1.43 & & 0 & Steel grade \\
\hline 10 & $\begin{array}{l}\mathrm{H} 26 \\
\text { (LY }\end{array}$ & $\begin{array}{l}\times 140 \times 12 \\
253)\end{array}$ & & $\begin{array}{c}\text { D16-16 } \\
(\mathrm{SD} 295)\end{array}$ & 0.098 & & 3.00 & & 0 & Steel grade \\
\hline
\end{tabular}

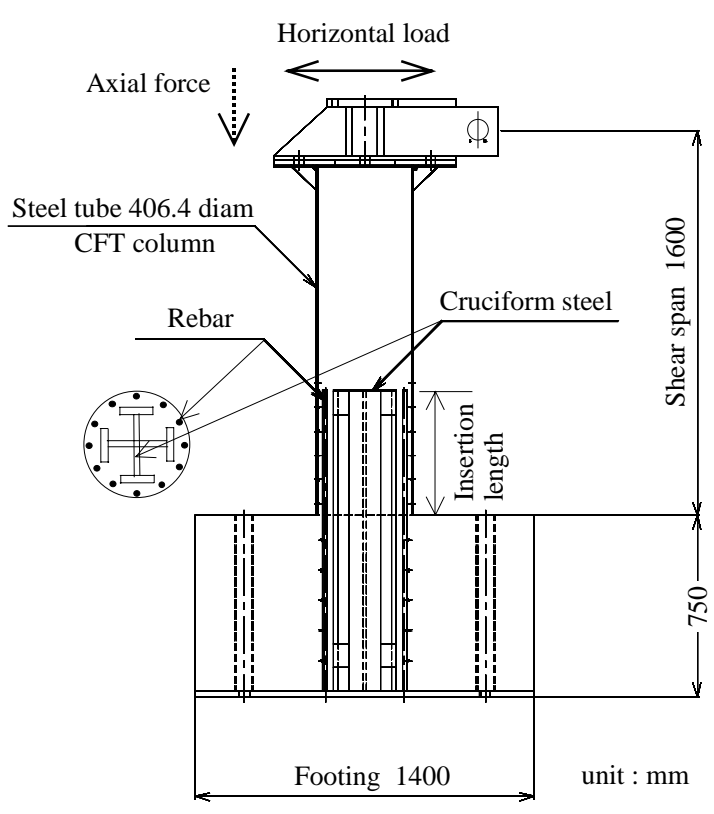

Fig. 1 Geometry of the specimen

\subsection{Test results}

a) Fracture mode

All the specimens for this test were designed in such a manner that they would fail from bending fracture of inserts. Nevertheless, both the bending fracture of CFT column and that of inserts occurred in the test. The fracture mode was assessed by the strain of the inserts, local buckling of the steel tube and cracking in the footing. Figures 3 and 4 show the views of the fractured specimens.

In the case of CFT tube bending fracture, the steel tube buckled locally near the insert tip at around the maximum load. Due to the cracking induced by the development of locally buckling and low cycle fatigue at the top of locally buckled portion, the specimen reached the ultimate state. On the other hand, the cracking in the footing surface, which was observed from yield point to maximum load, ceased growing as the local buckling developed.

In the case of bending fracture of inserts, no local buckling was found in the steel tube; the axial strain of the insert cruciform steel and rebars developed as the 
Table 2 Maximum load and fracture mode

\begin{tabular}{|c|c|l|c|c|}
\hline $\begin{array}{c}\text { Specimen } \\
\text { No. }\end{array}$ & $\begin{array}{c}\text { Experimental } \\
\text { max.load }(\mathrm{kN})\end{array}$ & \multicolumn{1}{|c|}{ Fracture mode } & \multicolumn{2}{|c|}{ Calculated bending strength $(\mathrm{kN})$} \\
\cline { 4 - 5 } & & CFT column & Insert \\
\hline JTSC-1 & 313.4 & CFT column bending fracture & 317.7 & 188.0 \\
\hline JTSC-2 & 455.3 & CFT column bending fracture & 429.7 & 282.3 \\
\hline JTSC-3 & 580.0 & Insert bending fracture & 551.8 & 348.9 \\
\hline JTSC-4 & 563.0 & Insert bending fracture & 551.1 & 351.8 \\
\hline JTSC-5 & 448.0 & CFT column bending fracture & 430.9 & 276.4 \\
\hline JTSC-6 & 341.0 & Insert bending fracture & 432.4 & 283.5 \\
\hline JTSC-7 & 467.2 & CFT column bending fracture & 461.5 & 299.3 \\
\hline JTSC-8 & 468.9 & CFT column bending fracture & 487.4 & 300.1 \\
\hline JTSC-9 & 456.1 & Insert bending fracture & 427.8 & 247.1 \\
\hline JTSC-10 & 433.9 & Insert bending fracture & 452.8 & 262.6 \\
\hline
\end{tabular}

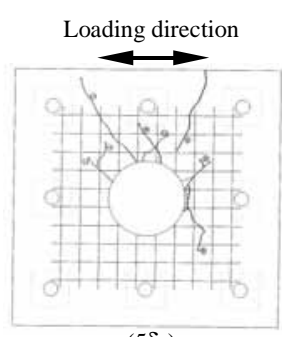

$\left(5 \delta_{\mathrm{y}}\right)$

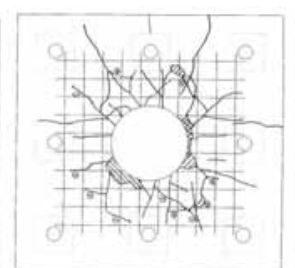

$\left(7 \delta_{y}\right)$

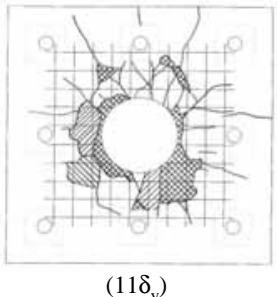

$\left(11 \delta_{\mathrm{y}}\right)$

Fig. 2 Crack propagation in upper surface of concrete footing (JTSC-9)

loading cycle increased, resulting in floating up of the steel tube from the footing surface, and separation of concrete in the vicinity of the boundary between steel tube and footing. There were cases where exposed rebars had broken.

Figure 2 illustrates the cracking status in the upper surface of footing concrete of JTSC-9 broken at the joint, at the time of initial cracking observed $\left(5 \delta_{\mathrm{y}}\right)$, maximum load $\left(7 \delta_{\mathrm{y}}\right)$ and near the ultimate strain $\left(11 \delta_{\mathrm{y}}\right)$. The circle at the center represents the steel tube section.

b) Load-displacement relationship

Table 2 shows the experimental maximum load of each specimen with calculated paper bending strength of CFT member and insert. The bending strength of the CFT member was calculated according to the Design standard for railway structures and commentary for Seismic design ${ }^{3)}$ (hereinafter referred to as "Seismic Design Standard"). In this calculation, the distance from loading point

to insert tip was taken as the shear span, and the maximum bending moment $\mathrm{M}_{\mathrm{m}}$ was obtained; the magnitude of $\mathrm{M}_{\mathrm{m}}$ was divided by the shear span to determine the magnitude of load at the loading point. The bending strength of the insert was calculated to conform to the Hybrid Structure Design Standard, assuming a circular SRC section in the boundary between footing and steel tube. The figures in the shaded cells represent the calculated strength corresponding to the fracture mode. In the case of CFT column bending fracture, there is good agreement between the calculated bending strength of the CFT column and experimental maximum load. In contrast, in the case of insert bending fracture, the experimental maximum load significantly exceeds the calculated bending strength. Considering such a large difference, we can conclude that predicted fracture (bending fracture of the insert) did not take place.

c) Relationship between horizontal load and column head displacement

Figures 5 and 6 show the load hysteresis curves of

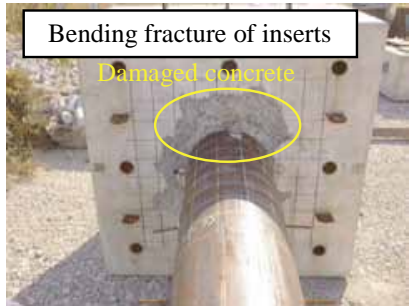

Fig. 3 View after loading (JTSC-9)

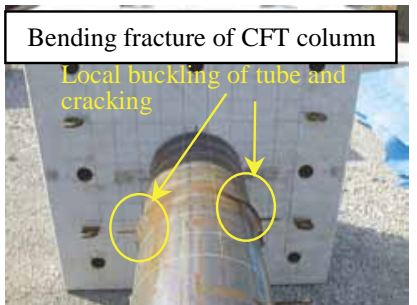

Fig. 4 View after loading (JTSC-2)
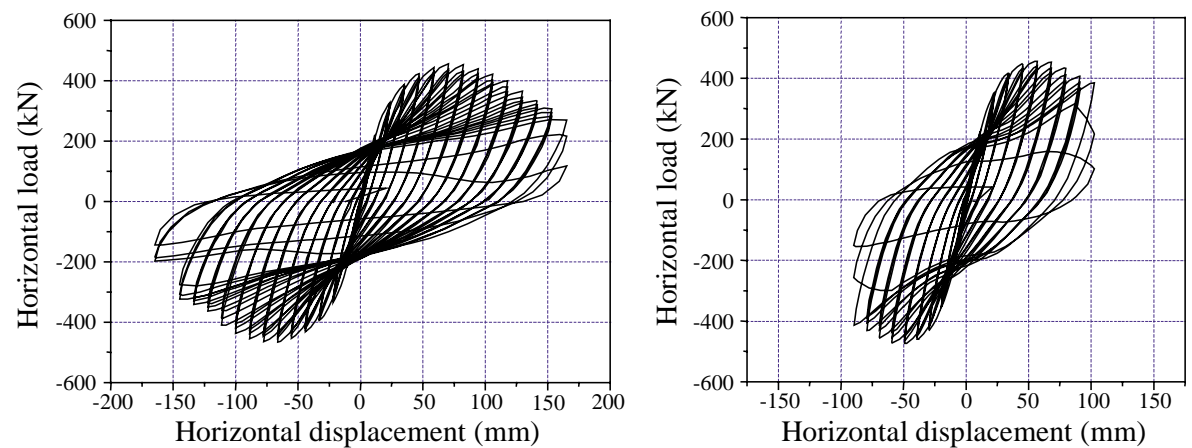

Relationship between horizontal load and column head

Fig. 5

JTSC-9

Fig. 6 JTSC-2 


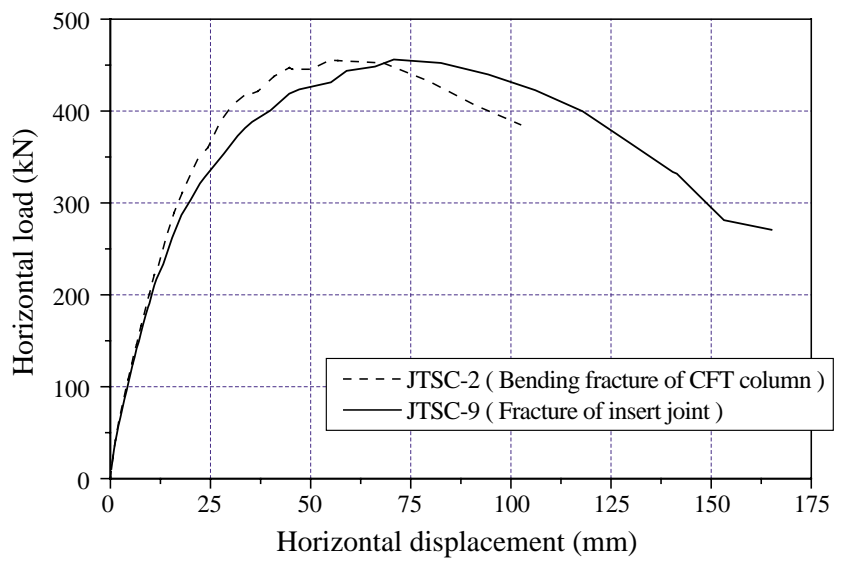

Fig. 7 Comparison of envelopes of load-displacement relationships

JTSC-2 (CFT column bending fracture) and JTSC-9 (insert bending fracture), respectively, and Fig. 7 provides a comparison of envelopes of both cases. It has been said that the insert is prone to brittle fracture. However, as known from these graphs, the displacement at the maximum load and displacement up to the ultimate state are larger in the case of bending fracture of inserts than the case of CFT column bending fracture, offering qualitatively higher ductility.

This can be explained by the fact that, with CFT column bending fracture, the structural performance continues to degrade because of local buckling of the steel tube, and finally, the ductility is limited by cracking from low cycle fatigue. On the other hand, with insert bending fracture, the deterioration depends upon the relatively slow progress of concrete damage in the footing surface at the steel tube base, resulting in greater ductility. Furthermore, the shape of the hysteresis curve demonstrates that high energy absorbing capability of the CFT structure is sufficiently maintained even at the bending fracture of inserts.

\section{Evaluation of the load-carrying capacity of the inserts}

The Hybrid Structure Design Standard considers the following three fracture modes of the joint with cruciform steel/rebar inserts.

- Yielding failure of steel tube at the joint

- Bending fracture of inserts

- Shear fracture of inserts

In the study, the yielding failure of steel tube at the joint and bending fracture of inserts is smaller between the bending strength of CFT column (ultimate strength Mu calculated by the Hybrid Structure Design Standard) multiplied by 1.4 and the bending strength of RC or SRC beam is multiplied by 1.3 , is taken as the design moment, that is, validation reference for the bending strength of each member. This prescription considers the largest difference between past experimental results and calculated strengths, and is based on the principle that the joint will not fail before the fracture of column or beam.

As for the bending strength of CFT member, a study ${ }^{1)}$ published after the edition of the Hybrid Structure De- sign Standard proposes $\mathrm{M}_{\mathrm{m}}$ which is obtained by multiplying $\mathrm{M}_{\mathrm{u}}$, involving the equivalent plastic hinge given as a function of the axial force ratio.

In the design of the specimens, the bending strength of the inserts were set at a value equal to or less than that of the CFT column, in order to focus upon the study of bending failure of the inserts. However, as mentioned earlier, no specimens showed the predicted fracture mode, with significant disagreement between test results and calculation.

Considering such disagreement, we will study below corrections of the current method to calculate the bending strength of inserts.

The following are possible causes for the significant difference between design bending strength and test results of the inserts.

(1) According to the conventional design practice, the weak axis member of the cruciform steel (i.e., member whose web is normal to the loading direction) is ignored in the calculation of the bending strength.

(2) By the effect of steel column to restrain the concrete, the strength of concrete in the axial direction increases. The calculation does not take into account this phenomenon.

We corrected the calculation method as follows to reflect the effect of these points.

The weak axis member of the cruciform steel is also included in the bending strength calculation (corrected calculation 1). Instead of the strain at the concrete compressive fiber, 0.0035 , specified for the calculation of bending strength of SRC member, the compressive strain at the outermost fiber of concrete is used to calculate the bending strength of CFT member ${ }^{3)}$, to reflect the concrete restraining effect by the steel tube, as with CFT member. (corrected calculation 2)

The yield stress of the steel tube is supposed to work as a concrete restraining force in the circumferential direction, since the strain in the circumferential direction was around the yield point in any specimen in the test. Under this supposition, the compressive strength corrected as follows is used on the basis of the references by Park, R. et al. ${ }^{4)}$ and Mander, J.B. et al. ${ }^{5}$. (corrected calculation 3 )

The restraining stress $f_{l}$ is given by

$f_{l}=2 t \cdot f_{y} / D$

here

$f_{y}=$ Yield stress of steel tube

$D=$ Steel tube diameter

$t=$ Steel tube wall thickness

The compressive strength of concretein $f_{c c}$ in this case is given by

$f_{c c}^{\prime}=f_{c}^{\prime}\left(2.254 \sqrt{1+\frac{7.94}{f_{c}^{\prime}}}-2 \frac{f_{l}}{f_{c}^{\prime}}-1.254\right)$

where

$f_{c}=$ Unconfined compressive strength of concrete

As demonstrated by the values in Table 3, the experimental magnitudes of bending strength of the inserts can be predicted with a much improved accuracy, by the calculation with fully-plastic moment, and taking into account the weak axis member and concrete restraining 
Table 3 Comparison between maximum load and calculated strength

\begin{tabular}{|c|c|l|c|c|c|}
\hline \multirow{2}{*}{$\begin{array}{c}\text { Specimen } \\
\text { No. }\end{array}$} & \multirow{2}{*}{$\begin{array}{c}\text { Experimental } \\
\text { max.load } \\
(\mathrm{kN})\end{array}$} & \multirow{2}{*}{$\begin{array}{c}\text { Fracture } \\
\text { mode }\end{array}$} & & \multicolumn{3}{|c|}{$\begin{array}{c}\text { Calculated strength of CFT column } \\
(\mathrm{kN})\end{array}$} \\
\cline { 5 - 6 } & & & $\begin{array}{c}\text { calculation } \\
1\end{array}$ & $\begin{array}{c}\text { calculation } \\
2\end{array}$ & $\begin{array}{c}\text { calculation } \\
3\end{array}$ \\
\hline JTSC-1 & 313.4 & CFT column & 229.4 & 243.6 & 318.8 \\
\hline JTSC-2 & 455.3 & CFT column & 321.6 & 344.5 & 466.9 \\
\hline JTSC-3 & 580.0 & Insert & 383.4 & 411.0 & 557.3 \\
\hline JTSC-4 & 563.0 & Insert & 390.1 & 416.9 & 518.8 \\
\hline JTSC-5 & 448.0 & CFT column & 329.5 & 351.6 & 475.3 \\
\hline JTSC-6 & 341.0 & Insert & 283.5 & 294.4 & 343.2 \\
\hline JTSC-7 & 467.2 & CFT column & 318.0 & 344.1 & 479.8 \\
\hline JTSC-8 & 468.9 & CFT column & 321.0 & 349.8 & 509.4 \\
\hline JTSC-9 & 456.1 & Insert & 275.7 & 303.9 & 414.9 \\
\hline JTSC-10 & 433.9 & Insert & 306.8 & 322.1 & 427.0 \\
\hline
\end{tabular}

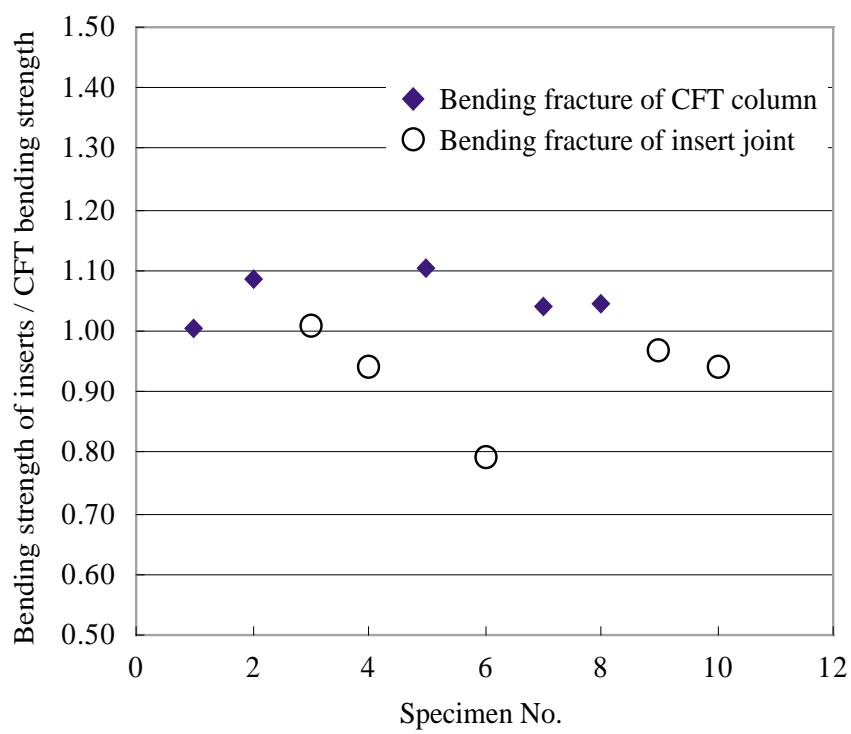

Fig. 8 Bending stress ratio of CFT column and inserts

effect.

Figure 8 shows the ratio of bending strength of the inserts (corrected calculation value 3 ) to that of CFT column (converted from the load at the loading point). Since this ratio of the specimens of the present test lies in a narrow range from 0.9 to 1.1 , it is difficult to predict which fracture mode would occur for each specimen. However, as shown in the Figure, different fracture modes distinctively distribute around the ratio of 1.0 .

The ratio of JTSC-3 is 1.01, therefore either fracture mode would take place with approximately the same probability. In conclusion, it is possible to predict the fracture mode by the bending strength ratio.

The insert joint section is designed by the current assessment method so as to present a ratio of about 1.9 or over, if expressed by the evaluation technique of Fig. 8. We know that the evaluation has been (excessively) conservative for inducing insert bending fracture, under the principle of avoiding joint fracture preceding mode.

\section{Design method of the insert joint}

The alternating loading test revealed that, even in the case of insert bending fracture, there is little risk of brittle fracture, and the subject configurations offer an excellent energy absorbing capability.

However;

- There remain unknown points about the behavior at further decreased ratios of the strength of the inserts to that of CFT member.

- It is easier to repair the damaged tube than replacing the damaged inserts.

- Through the review of the method to evaluate the bending strength of inserts, it will be possible to design more compact inserts.

For these reasons, the joint fracture preceding mode is not allowed when designing the insert by following the design principle. In designing inserts, therefore, it is necessary to provide a bending strength (moment) higher than that of CFT column at the same section.

It should be noted that, when the possible variance of calculation accuracy of each bending strength is considered, the strength should be conservatively determined. As for the bending strength of the CFT column, calculation may underestimate it by up to $10 \%$ in terms of the experimental value, as revealed by the results of the previous loading test with a simple CFT column ${ }^{1)}$ and those of the present test with 22 specimens in total. As for the bending strength of inserts in contrast, even the calculated maximum value is about the same as the experimental value, that is, calculated values are generally equal to or less than experimental results.

Hence, we can achieve conservative assessment by designing a strength of inserts 1.1 times as large as the bending strength of CFT column.

It is reasonable to apply (3) when assessing the safety for bending fracture of inserts.

$$
\gamma_{i} \cdot \frac{M_{d}}{M_{u d}} \cdot \frac{\ell_{j}}{\ell_{c}} \leqq 1.0
$$

where,

$M_{d}$ : Design bending moment. $M_{d}$ is the smaller value between the bending strength of the CFT column and the beam. In the case of the CFT column, $\mathrm{M}_{\mathrm{d}}$ is equal to 1.1 times the maximum bending strength calculated by the Seismic Design Standard. In the case of RC or SRC beam, $\mathrm{M}_{\mathrm{d}}$ is equal to 1.3 times the bending strength calculated by the RC standard ${ }^{6}$ or Hybrid Structure Design Stan- 
dard.

$M_{u d}$ : Bending strength of inserts (fully-plastic moments of steel and concrete are used in calculation)

$l_{j}=$ Span from loading point (bending moment $=$ zero) to the steel tube base

$l_{c}=$ Span from loading point (bending moment $=$ zero) to the tip of insert

When the bending strength of the beam is used as $M_{d}$, $l_{j}$ is equal to $l_{c}$.

In almost all cases of assessment of the bending strength of inserts by this method, the bending moment of CFT column is used to determine the design bending moment Md. This method provides a section with a bending strength decreased by about $55 \%$ (from 1.9 to 1.1 ) in terms of the strength by the current evaluation method.

\section{Conclusions}

Based on the experimental results, the load carrying capability and ductility of CFT columns with such a type of joint were evaluated. The results of the study are summarized as follows.

(1) It has been said that inserts are prone to brittle failure. If the CFT/insert strength ratio is similar to that of the present test, however, brittle failure does not occur even in the case of bending fracture of the inserts, and a satisfactory ductility is provided.

(2) The bending strength of the inserts can accurately be evaluated, through calculation of the fully-plastic moment of the section, involving the contribution of weak axis member of the cruciform steel and concrete restraining effect by steel tube.

(3) For assessing the safety of the inserts, the bending strength of CFT member multiplied by a factor of 1.1 is taken as the design bending moment, and is multiplied by the ratio of spans to each failure point. This technique ensures a suitable safety margin.

\section{References}

1) K.Murata, M.Yamada, M.Ikeda, M.Takiguchi, T.Watanabe, M.Kinoshita: Review of the ductility of concrete filled circular steel columns, Proceedings of the Japan Society of Civil Engineers, No.640/I-50, pp.149 to $163,2000$.

2) Railway Technical Research Institute, under the editorship of Railway Bureau of Ministry of Transport : Design standard for railway structures and commentary, Steel-concrete hybrid structures, Maruzen, 1998.

3) Railway Technical Research Institute, under the editorship of Railway Bureau of Ministry of Transport : Design standard for railway structures and commentary, Seismic design, Maruzen, 1999.

4) Park,R., and T.Paulay : Reinforced Concrete Structure, Wiley, New York, p.769, 1992.

5) Mander,J.B., M.J.N.Priestly, and R.Park : Theoretical Stress-Strain Model for Confined Concrete : Journal of the Structural Division, ASCE, Vol.114, No.8, pp.1804-1826, 1998.8 .

6) Railway Technical Research Institute, under the editorship of Railway Bureau of Ministry of Transport : Design standard for railway structures and commentary, Version in SI unit system (Concrete structures), Maruzen, 1999. 